Elaboración de un plan estratégico de Social Media Marketing para obtener mayor visibilidad y Engagement en la Universidad Adventista de Bolivia http://doi.org/10.33996/revistaenfoques.v1i4.22

No. 4 | Volumen 1 | Octubre - Diciembre 2017 http://revistaenfoques.org ISSN: 2616 - 8219

\section{ELABORACIÓN DE UN PLAN ESTRATÉGICO DE SOCIAL MEDIA MARKETING PARA OBTENER MAYOR VISIBILIDAD Y ENGAGEMENT EN LA UNIVERSIDAD ADVENTISTA DE BOLIVIA}

\author{
DEVELOPMENT OF A STRATEGIC PLAN FOR SOCIAL MEDIA MARKETING \\ TO OBTAIN GREATER VISIBILITY AND ENGAGEMENT IN THE UNIVERSITY \\ ADVENTIST OF BOLIVIA
}

Joselo Alejandro Cáceres Dávila

\begin{abstract}
Resumen
Investigación cuyo propósito fue implementar el plan de Social Media Marketing enfocado a incrementar la visibilidad y el Engagement de la Universidad Adventista de Bolivia, a través del análisis de la problemática que atraviesa la institución actualmente al no tener buena gestión y administración de sus recursos tecnológicos. El diseño metodológico fue un enfoque cuantitativo con un tipo de estudio descriptivo, también se realiza una auditoría en las redes sociales primeramente para determinar la situación actual y los lugares que ocupan la competencia respecto el Engagement y la visibilidad, los instrumentos utilizados para la recolección de datos fueron: encuesta a los estudiantes universitarios, observación equipo de marketing y una entrevista al Director del departamento, auditoría de las redes sociales con medición del Engagement, donde se pudo evidenciar el problema que atraviesa la U.A.B. Se realizó un análisis F.O.D.A. Se concluye proponiendo la contratación de un community manager e implementar el plan Social Media Marketing, con estrategias basados en el modelo SOSTAC, para incrementar la visibilidad $y$ Engagement.
\end{abstract}

Palabras clave: Social media; Engagement; marketing, community manager
Joselo Alejandro Cáceres Dávila caceres.joselo@gmail.com Universidad Adventista de Bolivia, Bolivia Licenciado en Ingeniería Comercial de la Universidad Adventista de Bolivia. Diplomado en Marketing Digital, Diplomado en Educación Superior, Especialidad en SISCO-System. Consultor Independiente con amplia experiencia en empresas públicas y privadas.

\begin{abstract}
Research whose purpose was to implement the Social Media Marketing plan focused on increasing the visibility and Engagement of the Adventist University of Bolivia, through the analysis of the problem that the institution is currently facing as it does not have good management and administration of its technological resources. The methodological design was a quantitative approach with a type of descriptive study, an audit is also carried out in the social networks first to determine the current situation and the places that occupy the competition regarding the Engagement and visibility, the instruments used to collect data were: survey of university students, observation of the marketing team and an interview with the Director of the department, audit of social networks with measurement of Engagement, where it was possible to demonstrate the problem that the UAB is going through An F.O.D.A. analysis was performed. It concludes by proposing the hiring of a community manager and implementing the social media marketing plan, with strategies based on the SOSTAC model, to increase visibility and Engagement.
\end{abstract}

Key words: Social media; Engagement; marketing, community manager

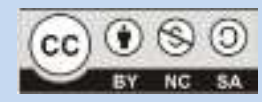

Revista Enfoques

Artículo recibido junio 2017 | Arbitrado entre ago-sep 2017 | Publicado en octubre 2017 


\section{INTRODUCCIÓN}

El vertiginoso desarrollo de las redes sociales es la respuesta a una demanda por parte de los usuarios de mantenerse comunicados entre sí. Compartir vivencias, situaciones y opiniones con diferentes personas forma parte de nuestra naturaleza social que ha integrado estas herramientas dentro de su vida diaria. Las nuevas vías de comunicación pueden ser aprovechadas por las empresas como un canal más dentro de sus estrategias de comunicación, que bien utilizadas y gestionadas por un community manager, les pueden servir para tener una conexión directa tanto con clientes actuales como potenciales.

El Social Media Marketing ha ofrecido una gran variedad de nuevas oportunidades a las empresas para promocionar su marca, productos y servicios. Cada día la repercusión de los medios sociales en los usuarios es mayor e influye en su decisión de compra. Sin embargo, parece que todavía no está claro qué beneficios reales reporta el Social Media Marketing a las empresas.

Las tecnologías de información son los elementos impulsores del actual desarrollo de la sociedad y del conocimiento a nivel global. Gracias a la tecnología, la forma de interactuar entre las personas especialmente por medio de las redes sociales es una oportunidad para hacer conocer como institución la imagen característica, poder tener más visibilidad y tener el compromiso de nuestra audiencia digital.

En la actualidad la Universidad Adventista de Bolivia no cuenta con un plan estratégico de Social Media Marketing, por lo tanto carece de presencia adecuada en los medios sociales. Estos medios sociales representan la oportunidad de ventaja competitiva para las instituciones. Además, tampoco crean elementos que sean atractivos, porque todo lo realizan de forma empírica, pero al no crear contenido atractivo se pierde la oportunidad de generar relaciones con los clientes.

Ahora bien, la idea del Social Media Marketing es conectar a los consumidores y audiencia de la institución para tener mayor visibilidad dentro del mundo virtual, ya que existen 1090 billones de visitas diarias solo en Facebook, esta es una gran oportunidad para darse a conocer como institución y así traspasar las barreras nacionales llegando a tener un alcance global. Al no poseer un plan de Social Media Marketing no se cuenta con una comunicación efectiva con los clientes, ya que en la actualidad los clientes desean ser escuchados, quieren tener cierto grado de incidencia en las decisiones que se toman como institución a diferencia del marketing tradicional donde son otros los objetivos perseguidos. La idea de esto es establecer una relación social, saber qué piensan acerca de nosotros y poder entender que es lo que quieren las personas a través de una escucha activa. Antes no existía la posibilidad de llegar a tener esta comunicación efectiva, gracias a la tecnología hoy lo se puede utilizar alcanzando muchos logros institucionales.

Por ello, la intención de la investigación base de este artículo, averiguar cómo se podía incrementar la visibilidad y el nivel de Engagement, desde la perspectiva de los procesos de gestión administrativa en relación a los recursos tecnológicos, mediante la implementación de un plan estratégico de Social Media Marketing en la $U A B$, teniendo como hipótesis de estudio, que la gestión de recursos tecnológicos sustentado en un plan estratégico de Social Media Marketing incrementará la visibilidad y el nivel de Engagement de la Universidad Adventista de Bolivia. 
Ante lo explicado, se exponen las bases teóricas de la investigación. En el presente las redes sociales no constituyen una moda, son construcciones de nuevas formas de comunicación, que gozan de un escenario propio con reglas y procedimientos que no solo permite conversar, sino compartir y participar de resto de la comunidad de usuarios.

Dentro de este contexto las marcas ocupan un lugar protagonista. Las ventajas que ofrecen las redes sociales para la construcción de valor y comunicación de valores corporativos, han permitido nuevas estrategias de marketing ocupando mucha más labor en los departamentos de comunicación, lo que da nuevos métodos de venta a diferencia de los canales tradicionales.

Gálvez (2015) declara que se denomina Social Media Marketing aquella parcela que, encuadrada dentro de la filosofía del marketing empresarial, centra su estrategia en torno al uso de herramientas 2.0 basadas en la participación social y la inteligencia colaborativa. Es necesario establecer acciones bien definidas enmarcadas en los planes marketing empresarial que ayuden y guíen el camino para poder obtener una máxima eficiencia.

La asociación americana de marketing AMA (American Marketing Association) por sus siglas en inglés ha ido transformando la definición de marketing y la conocemos actualmente como "La actividad, conjunto de instituciones, y procesos para crear, comunicar, entregar e intercambiar ofertas que tienen valor para los consumidores, clientes, asociados, y la sociedad en general"(Ros, 2008, s/n).

Para Maciá y Gosende (2011) el entorno tecnológico actual es altamente competitivo y sobre todo cambiante, surgen muchas innovaciones que van mejorando las herramientas y aplicaciones que se conoce. Es muy importante saber que herramientas vamos a ocupar para completar los objetivos de marketing.

En mi opinión, el término Social Media implica algo mucho más que una red social. El término media en el contexto de la Social Media se refiere a otra forma de comunicación de masas. Una red social como Linkedln es simplemente la herramienta que se usa para la comunicación. Así que la Social Media comprende las redes sociales, pero no viceversa. La propuesta estratégica de Social Media debe conducir a las redes sociales donde se elija estar activos porque eso va a identificar a los colegas, clientes y potenciales clientes con quienes se quiera comunicar.

Se debe destacar que la gran mayoría de herramientas son diferentes entre sí y apuntan a diversos grupos $u$ objetivos. Una empresa que no crea verdaderamente en el potencial de esta nueva forma de comunicar no podrá favorecer la implementación de una estrategia basada en las comunidades digitales. El espíritu de la compañía, el target al que va dirigido e incluso la media de edad de su plantilla son elementos que hay que tener en cuenta para saber exactamente cuán complejo será poner en marcha cambios de carácter estratégico (Lamelo, 2014).

El entorno de la Social Media es muy ágil y cambiante, existen muchos factores a considerar, factores que la empresa no necesariamente puede controlar. Al respecto Weber (2010) comenta “... tenga en mente que éstos [los medios de comunicación] continuarán cambiando, justo lo que era considerado un sitio web en 1993 difícilmente podrá ser considerado un sitio web hoy en día" (p. 91). 
Es muy importante que la empresa esté atenta al cambio, lo adopte como parte de su realidad cotidiana y lo asuma como una oportunidad y un reto, más que como una amenaza. Los Medios Sociales se presentan de muchas formas pero para el propósito del Marketing, se establecerá que las más populares se reducen a ocho herramientas (Zarella, 2010).

Retomando, el autor Weber (2010) comparte su punto de vista respecto a la elección de las herramientas del Social Media Marketing, comenta que quizá el mayor reto del mundo en línea es la velocidad con la cual noticias, ideas y opiniones pueden caer en la viralidad - tanto positiva como negativa -. Así que elija sus redes sociales con sumo cuidado.

Por lo tanto, hay que tener mucho cuidado con las herramientas de Social Media Marketing que se elija, pues marcará el rumbo de las empresas y la relación que se tenga con el grupo objetivo; una decisión estratégica a tomar muy en serio si se quiere tener éxito y cumplir los objetivos.

Los medios sociales son plataformas interactivas donde se crea contenido y es distribuido y compartido por las personas en la web. Los profesores Kaplan y Michael Haenlein de la escuela de Negocios ESCP definen a los medios de comunicación sociales como "grupo de aplicaciones basadas en Internet que se basan en los fundamentos ideológicos y tecnológicos de la Web 2.0, y que permiten la creación y el intercambio de contenidos generados por los usuarios" (González, 2015, s/n).

La definición de Engagement en castellano es compromiso, la Real Academia Española (2006) indica que deriva del latín compromissum. El significado de la palabra compromiso es "obligación contraída". Existen cientos de libros enteros sobre
Engagement Marketing donde se describen los beneficios y procesos de ocupar el compromiso de los clientes a una marca, bien o un servicio.

En el año 2009 se publicó un reporte de Confianza en el informe publicitario, que ayudó a arrojar luz sobre por qué se había tenido tanto éxito creando compromiso: Los consumidores de publicidad global confían más en amigos reales y en extraños virtuales.

El boca a boca se identificó como "La herramienta de venta más poderosa disponible."(Popovic, 2016, s/n). Popovic casi una década atrás llegó a la conclusión con base en su libro de que las recomendaciones de personas conocidas y el boca a boca fue la herramienta de venta más poderosa.

Para Kryder (2011) el community manager es el profesional que se encarga de las relaciones e interacciones entre una entidad y sus usuarios, clientes y público en general a través de los medios y redes sociales online.

\section{MATERIALES Y MÉTODOS}

En este trabajo de investigación se empleó el tipo de estudio descriptivo porque se detalló cómo son los hechos y cómo se manifiestan los fenómenos tanto internamente en la administración de los recursos tecnológicos como en los gustos y preferencias de los consumidores. Según Philip Kotler (2003), en su libro Fundamentos del marketing, plantea que el objetivo es describir cuestiones como el potencial de mercado de un producto o los parámetros demográficos y actitudes de los consumidores compran el producto.

El método utilizado fue el hipotético deductivo, está aplicado en tanto se tiene información previa de modelos similares, se parte de datos generales aceptados para llegar a la conclusión de tipo particular. La 
población estuvo compuesta por 1.536 estudiantes universitarios de la Universidad Adventista de Bolivia. Como muestra, después de la aplicación de parámetros estadísticos para ese efecto, fue de 307 personas. Para la recogida de la información requerida, se hizo uso de la encuesta, la entrevista y la observación.

Las fuentes secundarias consultadas fueron: Bibliografía, artículos indexados de internet, revistas económicas, datos del INE, enlaces a internet y periódico.

- Alexa ranking. Sitio donde se registra el tráfico de internet para poder determinar cuáles son los sitios web más visitados, los videos más vistos, las imágenes más descargadas. La finalidad es determinar el comportamiento del uso de las redes sociales.

- Redes sociales. Serán necesarias para ubicar a instituciones de educación superior que ya hacen uso del Social Media Marketing ya sea de forma empírica o de forma bien elaborada.

- Libros de marketing, marketing digital, Social Media Marketing. Esta documentación fomentó lo académico y justificación de los planteamientos. Así se pueden exponer los análisis, la planificación, la propuesta, ya que se llevó a cabo haciendo una comparación de diferentes teorías de los expertos, para así poder plantear un plan óptimo.

- Archive.org. Sitio web que almacena biblioteca digital por una organización sin ánimo de lucro dedicada a la preservación de archivos y sitios públicos de la web, recursos multimedia.

Por otra parte, se presenta a partir de la valoración metodológica de la encuesta el Análisis de los resultados.

Cuadro 1. Resumen de la encuesta realizada a los estudiantes de la Universidad Adventista de Bolivia

\begin{tabular}{|c|c|c|c|}
\hline ÍTEM & DESCRIPCIÓN & IMPORTANCIA & INTERPRETACIÓN \\
\hline 1 & Cuál es su género & $\begin{array}{l}\text { Poder segmentar a } \\
\text { que género estará } \\
\text { dirigido nuestra } \\
\text { propuesta }\end{array}$ & $\begin{array}{l}\text { Mayor cantidad de hombres en } \\
\text { nuestra población el } 55 \%\end{array}$ \\
\hline 2 & Cuál es su edad & $\begin{array}{l}\text { Conocer la edad de } \\
\text { nuestro segmento de } \\
\text { mercado }\end{array}$ & $\begin{array}{l}\text { El rango de edades de los } \\
\text { universitarios es de } 22 \text { a } 24 \\
\text { años }\end{array}$ \\
\hline 3 & Qué uso le da usted al internet & $\begin{array}{l}\text { Determinar cuál es el } \\
\text { uso que le dan los } \\
\text { estudiantes }\end{array}$ & $\begin{array}{l}\text { Se ocupa más el internet como } \\
\text { medio de comunicación un } 80 \% \\
\text { así lo confirma }\end{array}$ \\
\hline 4 & $\begin{array}{l}\text { Sigue usted en los medios } \\
\text { sociales a la UAB (Facebook, } \\
\text { Twitter, Youtube, Instagram) }\end{array}$ & $\begin{array}{l}\text { Me permite conocer } \\
\text { el nivel de Engagement } \\
\text { de la UAB }\end{array}$ & $\begin{array}{l}23 \% \text { sigue a la UAB en los } \\
\text { medios sociales }\end{array}$ \\
\hline
\end{tabular}




\begin{tabular}{lll}
\hline ÍTEM DESCRIPCIÓN & IMPORTANCIA & INTERPRETACIÓN \\
\hline
\end{tabular}

$5 \quad$ Cuánto tiempo pasa conectado a internet semanalmente

6

Qué dispositivo usa por lo general para conectarse a internet

7 Valore la importancia del correo electrónico

8

Valore la importancia de la mensajería instantánea

$9 \quad$ Valore la importancia de las investigaciones y lecturas

1010 Valore la importancia de las redes sociales

11 Qué uso le da a las redes sociales

12

12 Cuál es el medio de comunicación digital que recibe más publicidad

1313 A través de que medio se enteró de la Universidad Adventista de Bolivia

14 Cuál medio social es el que ocupas más
Saber cuánto tiempo dedican al internet

Conocer cuáles son los medios por los cuales se conectan a internet

Conocer si este medio nos va a servir para nuestro plan

Saber si a ellos les gusta estar conectados

Saber si usan el internet para realizar investigación académica

Determinar cuán importante es para ellos las redes sociales

Saber cuáles son los usos que ellos le dan a las redes sociales para poder justificar nuestro trabajo

Saber si ellos están recibiendo información de los medios sociales

Saber si las redes sociales se están ocupando o que medios están siendo utilizados

Conocer cuál es la herramienta social por la cual los estudiantes se manejan
Las persona navegan un promedio de 6 a 15 horas semanalmente una $63 \%$ de los universitarios

Los universitarios se conectan en la laptop y celular en la misma proporción del $49 \%$ al internet.

El correo electrónico es en un $45 \%$ bastante importante

El $81 \%$ piensa que los sistemas de mensajería tienen mucha importancia

Hay poca importancia en la investigación y lectura con un $46 \%$

El 74\% determina que las redes sociales tienen mucha importancia

El $51 \%$ ocupan las redes sociales para contactarse con otras personas

El $89 \%$ de usuarios piensan que reciben más publicidad de las redes sociales

El 89\% conoció la universidad por amigos y familia las recomendaciones

El $92 \%$ afirma que los medios sociales que más ocupan son Facebook y Google + 


\section{Conclusiones del resultado de la encuesta}

Después de haber realizado la encuesta a los estudiantes de la Universidad Adventista de Bolivia se pudo obtener mayor información sobre el perfil del estudiante universitario, por ello se afirma con los datos estadísticos que el Engagement es muy poco con nuestras redes sociales y se sustentó la viabilidad del proyecto.

\section{Conclusiones del resultado de la entrevista}

Según la entrevista realizada, la Universidad Adventista no cuenta con un plan de marketing aplicado, sí existe como documento elaborado por la Universidad para la evaluación, pero no se cumple a cabalidad ni se ejecuta; tampoco se tiene un personal dedicado a las redes sociales, ni existe un plan ni estructura sobre el trabajo para el uso de las redes sociales, tampoco se tiene administración y gestión de todas las redes sociales de la UAB, únicamente se tiene la administración de la Facebook de la UA Bolivia, para la creación de contenidos y difusión de la UAB no existe un calendario, ni estrategias, ni métricas que permitan evaluar y conocer el desempeño como tal.

\section{RESULTADOS Y DISCUSIÓN}

Del trabajo de investigación realizado en el campus de la universidad adventista de Bolivia se pudo constatar la necesidad de mejorar el proceso de administración y la gestión de contenidos en los medios sociales para la ejecución de nuestro plan estratégico.

Etapa $\mathbf{N}^{\circ} \mathbf{1}$ Proponer proceso administrativo para mejorar el uso de la tecnología

Propuesta de mejora en el área de administración. Dentro del organigrama del departamento de Imagen Institucional \&
Marketing existe el papel del community manager y posee su manual de funciones. Se propone aplicar este manual de funciones existente al cargo correspondiente. En cuanto a la administración de los medios sociales no existe una persona contratada a pesar de estar en el organigrama. La propuesta es contratar a una persona a tiempo completo para que pueda realizar una correcta gestión de los medios sociales de la Universidad Adventista de Bolivia.

Etapa $\mathbf{N}^{\circ} \mathbf{2}$ Proponer proceso para gestión para mejorar el uso de la tecnología

Propuesta de gestión. Para poder conseguir este objetivo se propone el uso del documento formal "Brief", el cual es un conjunto de parámetros que regirán el desarrollo del proceso de diseño, esto ayudará a contar con una información cabal y organizar de mejor manera el cronograma del proceso, de recolección de información, definir el concepto y gestionar la entrega del diseño, para esto se presentan una serie de condiciones que ayudarán a definir el producto de comunicación.

Etapa $\mathbf{N}^{\circ} 3$ Aplicar el manual de marca de la UAB en la gestión de contenidos

Aplicación de manual de marca. La Universidad Adventista de Bolivia actualmente posee su manual de marca. Sin embargo, no se debe olvidar que el presente proyecto busca, fundamentalmente, incrementar el Engagement (compromiso) a la UAB, entendiéndose bien y en su representación a la marca de la UAB es el elemento más visible. Por lo tanto es imprescindible aplicar el uso correcto de la marca en cada publicación, interacción, generación de contenido y cualquier uso o actividad relacionada a la marca de la UAB. 
Etapa № 4 Desarrollo del plan estratégico de SSM

Ya teniendo en claro la persona responsable, sus funciones, la forma de gestionar el contenido, el uso y la aplicación correcta de la marca se pasa a desarrollar el plan. Este plan está basado en el modelo SOSTAC, la primera es realizar los análisis correspondiente a nuestra situación y posteriormente definir los objetivos, una vez definidas se pueden formular las estrategias; la segunda etapa es desarrollar las estrategias, y las acciones que se tomarán sin dejar de lado el control.

\section{Acciones estrategias y tácticas}

- Objetivo: Aumentar la visibilidad de la Universidad Adventista de Bolivia.

Estrategia: Promocionar a los estudiantes con sus testimonios por cada facultad

Tácticas: Redes sociales, Página web

Acciones: a) Postear al menos una vez a la semana en las redes sociales; b) Analizar a los alumnos integrales de cada carrera, cuáles son los estudiantes influyentes que apoyarán a mejorar la visibilidad; c) se deben publicar, al menos una vez por semana, una imagen inspiradora del estudiante $y$ un mensaje con palabras propias del mismo, la cual describa qué es lo que más le motiva a seguir estudiando; y d) Investigar cuáles son los contenidos más sobresalientes de nuestros pares en educación superior adventista. Cómo lo utilizan, qué les funciona o no funciona para poder aplicar a la universidad.

Estrategia: Promocionar a los docentes, personal con testimonios

Tácticas: Redes sociales; Página web

Acciones: a) Publicar imágenes en los medios sociales y en página web; b) publicar imágenes de los docentes y el personal universitario en las distintas actividades que realicen; c) Realizar marco o sellos de tiempo que identifiquen a la universidad en cada publicación de las imágenes; d) Publicar el mensaje propio de la persona; e) Realizar videos cortos con los testimonios; f) Elaborar videos cortos de 140 segundos donde las personas puedan expresar que es lo más hermoso de la UAB, y cuál sería su mensaje inspirador para los estudiantes; y g) Postear por los medios sociales este contenido que ha de ser elaborado de manera atractiva y dinámica.

Estrategia: Promocionar a los estudiantes de las UE que visitan nuestro campus.

Tácticas: Redes sociales

Acciones: a) Publicar fotografías en las redes sociales; y b) Hacer reseña de la UE para compartir en las redes sociales generando más atracción.

Estrategia: Transmitir online los distintos eventos de la institución.

Tácticas: Redes sociales

Acciones: a) Crear flyer de las transmisiones online; b) Realizar flyer para las redes sociales que mantengan informada a la comunidad; c) Promover actividades como semanas de oración, acto de graduación, son eventos sobresalientes que van atraer más visibilidad a la UAB; d) Realizar backstage en las distintas transmisiones; e) Ofrecer conversaciones introductorias con estudiantes de la UAB en los eventos más destacados de la universidad; f) Compartir estas entrevistas en los distintos medios sociales; g) Enviar boletines informativos; $y$ h) Remitir mensualmente un boletín con información de interés para la comunidad universitaria. 
- Objetivo: Generar Engagement para la Universidad Adventista de Bolivia

Estrategia: Conexión con personajes influyentes.

Tácticas: Redes sociales; Youtube

Acciones: a) Establecer relaciones auténticas a través de personas influyentes en el ámbito no solo del sector académico, también del ámbito espiritual. Para poder acceder a una red más amplia de personas y amplificar nuestro mensaje; b) Publicar contenido visual, multimedia de nuestras conexiones con personas influyentes, por ende compartir artículos y/o contenido que siga aportando valor a los seguidores; y c) Motivar a los fans a que formen parte de la página haciendo de manera interactiva juegos como los puzles; replicar dentro la página web institucional la misma dinámica.

Estrategia: Mensajes emotivos en fechas festivas conmemorativas.

Tácticas: Redes sociales

Acciones: a) Crear imágenes en las fechas emotivas correspondientes no olvidando la marca uabense con mensajes emotivos; b) Ocupar las redes sociales para publicar los mensajes creados; c) Agradecer a los seguidores y Fans; d) Publicar mensajes de agradecimiento cuando haya respuestas que hayan resaltado logros institucionales, tienen el mismo efecto o más que si lo haces en persona; y e) Diseñar imágenes con los seguidores destacados para reconocer la fidelidad que tienen a la marca uabense.

Estrategia: Escuchar y hablar con los seguidores y los fans.

Tácticas: Redes sociales

Acciones: a) Escuchar todo lo que se dice en la red; leer todos los mensajes que los fans y seguidores postean en la red, incluyendo los mensajes privados; b) Responder, de manera óptima, los mensajes en el menor tiempo posible; y c) monitorizar todo lo que se habla después de las conversaciones.

\section{CONCLUSIONES}

En la auditoria de las redes sociales se puede apreciar una gran cantidad en la Universidad Adventista, pero ninguna está siendo gestionada de manera profesional. También se puede apreciar que cada unidad académica y de servicios posee de manera independiente su red social.

De los resultados obtenidos en la encuesta se puede considerar que no se tiene Engagement, debido a que existen puntos débiles mercadológicos y el plan de marketing propuesto fortalecería satisfactoriamente la visibilidad y el Engagement.

La Universidad Adventista de Bolivia no conoce las particularidades de su mercado ni tiene definido su mercado meta digital. Esto ocasiona que la promoción de sus servicios actuales sea ineficiente.

A pesar de que otras universidad adventistas utilizan redes sociales con el objetivo de alcanzar un mayor número de posibles clientes, sólo se limitan a publicar información sin una base, lo cual implica adoptar un plan de marketing basado en Social Media por completo.

El éxito de esta estrategia basado en Social Media Marketing depende en mayor grado de la conexión de la Universidad Adventista de Bolivia con sus estudiantes, profesores y personal administrativo. El uso de la creatividad en la redacción de contenido que se muestre a los usuarios y de la identificación que se logre con el mismo.

Se recomienda a la Universidad Adventista de Bolivia establecer un mercado digital meta que considere el perfil del cliente obtenido a partir del estudio de mercado, además de aprovechar las 
comodidades que otorgan las redes sociales para conocer las necesidades constantes de los clientes.

Se recomienda realizar un calendario editorial para gestionar las publicaciones que se hagan a través de las redes sociales.

El número de visitas se puede incrementar utilizando palabras clave, los buscadores de los sitio web, descriptores que permitan optimizar el posicionamiento de la Universidad Adventista en los motores de búsqueda como Google. Así como herramientas de analítica web, tales como Google Analytics, para medir los indicadores de rendimiento propuestos y generar informes mensuales, que faciliten la toma de decisiones.

De ser implantado, y con el propósito de medir y evaluar la eficiencia del plan propuesto, se sugiere dar seguimiento continuo, y de esa manera identificar las mejoras que pudieran efectuarse en las estrategias.

Es de carácter urgente realizar la contratación de un community manager que pueda realizar la administración y gestión de las redes sociales de la UAB. Se debe crear prontamente una cuenta en la red social Instagram, Linkeln para empezar a conectarnos y realizar conversaciones con los clientes.

Por último, certificar y verificar la autenticidad de las cuentas de los medios sociales que están creados y los que van hacer creados. Recuperar el control de las cuentas en las cuales el departamento de marketing no tiene el control.

\section{REFERENCIAS}

Gálvez Clavijo, I. (2015). Facebook para empresas y emprendedores. Málaga, España: IC Editorial. Disponible: http://site.ebrary.com/lib/bibliotecauna chsp/docDetail.action?docID=11335565

González, V. (2006). Real academia Española y asociación de academias de la Lengua Española. 1 edición. Madrid, España: Cartone

Kryder, C. (2011). Social media or social network? There's no simple semantic solution. Social media or social network? There's no simple semantic American

Lamelo, C. (2014). Follow Friday: método estratégico de comunicación 2.0 y márquetin digital. Barcelona, España: Editorial UOC

Maciá Domene, F., y Gosende Grela, J. (2011). Marketing con redes sociales. Madrid, España: Anaya Multimedia

Popovic, K. (2016). Uso del social media para subir el engagement (5ta.). U.S: Mc CRC Press

Ros, V. (2008). E-Branding. Disponible: https://books.google.com/books/about/ e_Branding.html?hl=es\&id=ASqC36N6A hU

Weber, L. (2010). Marketing en las redes sociales cómo las comunidades de consumidores construyen su negocio. México: Mc Graw-Hill

Zarella, D. (2010). The Social Media Marketing Book. Canada: O’Reilly Media 